\title{
Development of Hepatocellular Carcinoma in Patients with Chronic Hepatitis B Long After Achieving Hbsag Seroconversion: A Need for an Improved Hepatitis B Virus DNA Assay
}

She-Yan Wong ${ }^{1}$, Xiangdong David Ren ${ }^{2}$, and Hie-Won Hann ${ }^{1,3}$

${ }^{1}$ Division of Gastroenterology and Hepatology, Department of Medicine, USA

${ }^{2}$ Reniguard Life Sciences Inc, Exton, USA

${ }^{3}$ Liver Disease Prevention Center, Jefferson Medical College, Thomas Jefferson University Hospital, USA

\begin{abstract}
The ultimate goal of antiviral treatment is prevention of hepatocellular carcinoma (HCC). Currently the end point of successful antiviral treatment for patients with chronic hepatitis B is to achieve HBsAg loss or HBsAg seroconversion. We report two patients who successfully developed anti-HBs with or without antiviral therapy and yet developed HCC. Initial commercial assay showed negative HBV DNA for both patients. However, they were found to have detectable HBV DNA by a new laboratory-developed HBV DNA assay. These cases show that patients with HBsAg seroclearance continue to be at risk for HCC and surveillance for HCC should be continued. The diagnosis of occult hepatitis $B$ with an improved HBV DNA assays is also necessary as it is important for treatment for chronic HBV and prevention of HCC.
\end{abstract}

Keywords: Occult hepatitis B; Hepatocellular carcinoma; Negative hepatitis B surface antigen

\section{Introduction}

The ultimate goal of antiviral treatment is prevention of hepatocellular carcinoma (HCC). Currently the end point of successful antiviral treatment for patients with chronic hepatitis $\mathrm{B}$ (CHB) is to achieve hepatitis B surface antigen (HBsAg) loss or HBsAg seroconversion. However, studies showed that even those who had bona fide acute hepatitis $B$ with spontaneous production of anti-HBs, HBV DNA was found in the liver several decades later [1].

Occult hepatitis $\mathrm{B}(\mathrm{OHB})$ has been well described in the literature. It is defined as the presence of HBV DNA in liver tissue and/or serum with negative HBsAg. OHB is an important entity as it has been associated with HBV transmission through blood transfusions, chronic liver disease, and HCC [2]. Currently there are no guidelines for screening, but studies have shown that OHB is likely a risk factor for cryptogenic HCC [3]. Methods of diagnosis consist of livery biopsy or HBV DNA by polymerase chain reaction (PCR). Though the commercial method of PCR has had good sensitivity, false negatives can still occur [4].

Here we report two patients who successfully developed anti-HBs with or without antiviral therapy and yet developed HCC while being HBsAg(-)/ anti-HBs(+) and HBV DNA (-) by the commercial assay. However, they were found to have detectable HBV DNA by a new laboratory-developed HBV DNA assay.

\section{Case Report 1}

The patient is a 64 year old Asian female with no significant past medical history who initially presented with right shoulder pain. On physical examination, she showed no stigmata of chronic liver disease but a large firm mass was palpable in the right side of the abdomen reaching down close to pelvic rim. A $9 \times 10 \times 10 \mathrm{~cm}$ mass occupying the entire right hepatic lobe was found on MRI. The left lobe was free of tumor with no sign of cirrhosis. Laboratory work at that time revealed hemoglobin $16.3 \mathrm{gm} / \mathrm{dL}$, platelets $229,000 / \mathrm{mm}^{3}$, albumin $4 \mathrm{gm} / \mathrm{dL}$, total bilirubin $0.7 \mathrm{mg} / \mathrm{dL}$, aspartate transaminase $97 \mathrm{U} / \mathrm{L}$, alanine transaminase $17 \mathrm{U} / \mathrm{L}$, and alkaline phosphatase $98 \mathrm{IU} / \mathrm{L}$. She was $\mathrm{HBs} A g$ negative, anti-HBs positive, anti-HBc negative, HBV DNA undetectable and hepatitis $\mathrm{C}$ antibody negative. Alpha-fetoprotein (AFP) was $7,981 \mathrm{ng} / \mathrm{ml}$. One of her two daughters was $\mathrm{HBsAg}(+) / \mathrm{anti}-$ HBs(-). The other daughter was anti-HBs (+)/anti-HBc (+). The patient subsequently underwent a right hepatic lobectomy with pathology consistent with moderately differentiated HCC. Biopsy of the left lobe showed no fibrosis or cirrhosis. Three years later a lung metastasis (1 $\mathrm{cm}$ diameter) was noted and successfully removed by video assisted thoracic surgery. The pathology was again HCC. At this time serum samples at the time of initial HCC diagnosis and at lung metastasis (both negative for HBV DNA by the commercial assay), and the excised liver tumor were retrospectively examined by the new laboratory developed assay (see Materials and Method). Both serum samples were positive for HBV DNA at the level of 3271 copies $/ \mathrm{ml}$ and 52 copies $/ \mathrm{ml}$ respectively. The excised liver tissue was also positive for HBV DNA. This confirmed the diagnosis of HBV-related HCC and the patient was started on lamivudine $150 \mathrm{mg}$ daily. Subsequent sera have been HBV DNA negative by the new assay for the past several years. The patient has survived without further development of HCC or metastasis for the past 8 years and she has remained HBV DNA negative on lamivudine therapy. She is currently HBsAg(-)/anti-HBs(+) and HBV DNA (-).

\section{Case Report 2}

Patient is a 50 year old Asian male who presents with HCC. $\mathrm{He}$ reports being diagnosed with chronic hepatitis $\mathrm{B}$ on routine examination 10 years ago when he was found to be $\mathrm{HBsAg}(+)$. He was started on lamivudine and continued it for three years. Treatment

*Corresponding author: Hie-Won Hann, Liver Disease Prevention Center Division of Gastroenterology and Hepatology, Department of Medicine, Jefferson Medical College, Thomas Jefferson University Hospital, USA, Tel: 1-215-9555806; Fax: 1-215-955-0770; E-mail: hie-won.hann@jefferson.edu

Received July 25, 2013; Accepted August 19, 2013; Published August 21, 2013 Citation: Wong SY, Ren XD, Hann HW (2013) Development of Hepatocellular Carcinoma in Patients with Chronic Hepatitis B Long After Achieving Hbsag Seroconversion: A Need for an Improved Hepatitis B Virus DNA Assay. Clin Microbial 2: 127. doi: 10.4172/2327-5073.1000127

Copyright: $\odot 2013$ Wong SY, et al. This is an open-access article distributed under the terms of the Creative Commons Attribution License, which permits unrestricted use, distribution, and reproduction in any medium, provided the original author and source are credited. 
was discontinued when he showed HBsAg seroconversion; HBsAg (-)/ anti-HBs (+), HBeAg(-)/anti-HBe (+) and undetectable HBV DNA. Laboratory tests were routinely monitored and he remained well until an elevated AFP prompted an MRI that showed a $5 \mathrm{~cm}$ left lobe mass consistent with HCC. His serum was undetectable for HBV DNA by the commercial PCR assay. However given high suspicion for OHB, the serum was retested with our new assay. He was found to have 847 copies/ml of HBV DNA at the time of presentation of HCC. He was then restarted on lamivudine $150 \mathrm{mg}$ daily. Subsequent sera while on antiviral therapy were HBV DNA negative by the new HBV DNA assay.

\section{Methods and Materials}

\section{DNA isolation from the patient serum samples}

DNA was isolated from patient serum samples using the QIAamp DNA Blood Mini kit (Qiagen) according to manufacturers' instructions. Briefly, $200 \mu \mathrm{l}$ of sample was mixed with $200 \mu \mathrm{l}$ buffer $\mathrm{AL}$ and $20 \mu \mathrm{l}$ Protease $\mathrm{K}$, and incubated at $56^{\circ} \mathrm{C}$ for $10 \mathrm{~min}$. Pure ethanol $(200 \mu \mathrm{l})$ was added and mixed by vortexing. The mixture was then applied to a QIAamp Mini Column connected to a vacuum manifold via a disposable adaptor (to prevent cross contamination). The column was washed sequentially with $750 \mu \mathrm{l}$ buffer AW1 and $750 \mu \mathrm{l}$ buffer AW2 on the vacuum manifold, and spun at 14,000 rpm for $1 \mathrm{~min}$ to remove residual wash buffer. The viral DNA was eluted in $50 \mu \mathrm{l}$ of buffer EB. To prevent potential cross-contamination during centrifugation, the columns were wrapped with parafilm, and the aerosol-free centrifuge was cleaned and irradiated under an ultraviolet lamp before use.

\section{Laboratory-developed total HBV viral load assay}

A TaqMan real time PCR for HBV total viral load was developed using the primers (HBV1F, HBV1R) and the probe (HBVTAQ) described in [5], with modifications in the forward primer. A discontiguous megablast analysis revealed significant nucleotide polymorphism at the 3'-end of the forward primer (data not shown). Thus, the assay was supplemented with a new forward primer (HBV1Fa, 5'-tccccgtctgtkccttctc-3'). Briefly, $35 \mu$ PCR reactions were assembled using the LightCycler480 Probe Master Mix (Roche), $0.5 \mu \mathrm{M}$ HBV1F (5'-ccgtctgtgccttctcatctg-3'), $0.5 \mu \mathrm{M}$ HBV1Fa, 0.5 $\mu \mathrm{M}$ HBV1R (the reverse primer; 5'-agtccaagagtyctcttatgyaagacctt-3'), $0.1 \mu \mathrm{M}$ HBVTAQ probe (5'-6FAM-ccgtgtgcacttcgcttcacctctgc-BHQ1), and 17.2 $\mu \mathrm{l}$ of DNA purified from the patient samples. The PCR conditions were optimized in a LightCycler 480 instrument as $95^{\circ} \mathrm{C} 10$ min followed by 45 cycles of $95^{\circ} \mathrm{C} 10 \mathrm{sec}, 60^{\circ} \mathrm{C} 30 \mathrm{sec}$, and $74^{\circ} \mathrm{C} 10 \mathrm{sec}$. A plasmid carrying wild type $\mathrm{HBV}$ sequence that matches the primers and the probe was constructed and used for assay optimization. The same plasmid was serially diluted and included in each assay as concentration standards. The analytical sensitivity of the assay is 15-30 copies of viral DNA per ml of serum. The presence of $1 \mu \mathrm{g}$ of human genomic DNA did not generate any positive signal or diminish the signals for viral DNA (data not shown), indicating high sensitivity.

\section{Discussion}

OHB has been shown in several studies to be associated with the development of HCC $[3,6]$. Though awareness of the relationship is increasing, the diagnosis of $\mathrm{OHB}$ still presents to be a challenge. A high clinical suspicion and a reliable HBV DNA detection method are both important for the diagnosis. The HBV genome tends to have polymorphism which can affect the performance of the PCR primers and probe, and cause false negative detection. Commercial HBV DNA
PCR assays consist of only one set of primers/probe. Given the high rate of HBV DNA polymorphism, it is not surprising for any assay to have false negatives. In our assay, we took gene polymorphism into consideration and redesigned primers based on the BLAST analysis of all GenBank deposited HBV sequences. Although the cases presented here by no means prove that our assay is superior to the commercial assay, they do highlight the importance of a more reliable HBV DNA assay. Perhaps two or more sets of primers/probe are required in one assay can significantly reduce the chance of false negative detection. On the other hand, because the primer and probe sequences for the commercial assays are not readily available, it is difficult for us to prove that the two cases are indeed false negatives due to sequence mismatch. Thus, we do not yet know what exactly caused the discrepancy between our detection and the commercial detection. Differences in assay sensitivity and_DNA purification methods may also impact HBV detection to some extent.

How do we reconcile that a patient may have low levels of viral DNA in the circulation while being HBsAg negative? Previous reports showed that HBVs defective in HBsAg may not be secreted into the circulation but may remain active in replication inside hepatocytes, thereby causing HCC [7]. It is interesting to note that both the primary HCC and the corresponding serum specimens in Case \#1 are positive for HBV DNA. It is possible that the serum HBV DNA may be released directly from the dying tumor cells. Alternatively, the secreted virus may have an HBsAg mutation that escapes detection.

These two cases also demonstrate that despite HBsAg sero clearance, whether spontaneously or with antiviral therapy, the risk for HCC still exists. This is concerning because the success of antiviral therapy is often measured by HBsAg seroclearance. Yuen et al. has shown that patients with spontaneous HBsAg seroclearance do not signify eradication of HBV and may still develop HCC [8]. Papatheodoridis et al. similarly found that virological on-therapy remission did not eliminate the risk for HCC [9].

In conclusion, patients with $\mathrm{HBsAg}$ seroclearance continue to be at risk for HCC and surveillance for HCC should be continued. The diagnosis of OHB with an improved HBV DNA assays is also necessary as it is important for treatment for chronic $\mathrm{HBV}$ and prevention of HCC.

\section{References}

1. Yuki N, Nagaoka T, Yamashiro M, Mochizuki K, Kaneko A, et al. (2003) Long-term histologic and virologic outcomes of acute self-limited hepatitis $B$. Hepatology 37: 1172-1179.

2. Said ZN (2011) An overview of occult hepatitis B virus infection. World J Gastroenterol 17: 1927-1938.

3. Wong DK, Huang FY, Lai CL, Poon RT, Seto WK, et al. (2011) Occult hepatitis $B$ infection and HBV replicative activity in patients with cryptogenic cause of hepatocellular carcinoma. Hepatology 54: 829-836.

4. Lindh M, Hannoun C, Malmström S, Lindberg J, Norkrans G (2006) Lamivudine resistance of hepatitis $B$ virus masked by coemergence of mutations in probe region of the COBAS AMPLICOR assay. J Clin Microbiol 44: 2587-2589.

5. Loeb KR, Jerome KR, Goddard J, Huang M, Cent A, et al. (2000) Highthroughput quantitative analysis of hepatitis $B$ virus DNA in serum using the TaqMan fluorogenic detection system. Hepatology 32: 626-629.

6. Shi Y, Wu YH, Wu W, Zhang WJ, Yang J, et al. (2012) Association between occult hepatitis B infection and the risk of hepatocellular carcinoma: a metaanalysis. Liver Int 32: 231-240.

7. Lai MW, Yeh CT (2008) The oncogenic potential of hepatitis B virus rtA181T/ surface truncation mutant. Antivir Ther 13: 875-879. 
Citation: Wong SY, Ren XD, Hann HW (2013) Development of Hepatocellular Carcinoma in Patients with Chronic Hepatitis B Long After Achieving Hbsag Seroconversion: A Need for an Improved Hepatitis B Virus DNA Assay. Clin Microbial 2: 127. doi: 10.4172/2327-5073.1000127

Page 3 of 3

8. Yuen MF, Wong DK, Fung J, Ip P, But D, et al. (2008) HBsAg Seroclearance in chronic hepatitis B in Asian patients: replicative level and risk of hepatocellular carcinoma. Gastroenterology 135: 1192-1199.
9. Papatheodoridis GV Manolakopoulos S, Touloumi G, Vourli G, Raptopoulou Gigi M, et al. (2011) Virological suppression does not prevent the development of hepatocellular carcinoma in HBeAg-negative chronic hepatitis B patients with cirrhosis receiving oral antiviral(s) starting with lamivudine monotherapy: results of the nationwide HEPNET. Greece cohort study. Gut 60: 1109-1116. 